\title{
Physicochemical Property Analysis
}

National Cancer Institute

\section{Source}

National Cancer Institute. Physicochemical Property Analysis. NCI Thesaurus. Code C134259.

The tests performed to assess/determine physical and chemical characteristics of the drug substance. 